\title{
BOMBARDMENT-INDUCED SEGREGATION AND REDISTRIBUTION*
}

N. Q. Lam and $\mathrm{H}$, Wiederstch

Muterials Sclence and Technology Division

Argonne National Laboratory

Argonne, IL 60439 U.S.A.

\section{Apri1 1986}

The subminted manusceipt has been authored
by a contractor of the U.S. Government
Lnder contrect No. W-31-109ENG-38.
Accordingly. the U. S. Government retains
nonexclusive, rovalty-free license to publish
or reproduce the published form of thit
contribution, or ailow others to do so. for
$U$ S. Government purposes.

U S. Government purposes.

Invited perper to be published in the Proceedings of the International Symposium on Sputtering, Vienna, June 2-6, 1986, (Nuc1. Instr. Meth. B). * Work supported hy the U. S. Department of Energy, BES-Materials Sciences, under Contract $\mathrm{H}-31-109-$ Eng-38. 
BOMBARDMENT-INDUCED SEGREGATION AND REDISTRIBUTION*

N. Q. Lam and H. Wledersich

Materials Science and Technologr Division

Argonne National Laboratory

Argonne, IL 60439 U.S.A.

Apr11 1986

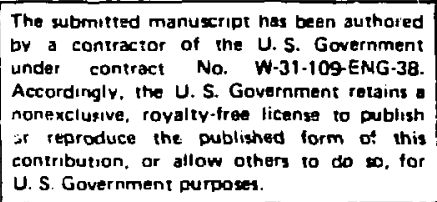

\section{DISCLAIMER}

This repon yas prepared as an account of work sponsored by an agency of the United States Government. Neither the United States Government nor any agency thereof, nor any of their employees, makes any warranty, express or implied, or assumes any legal liability or resporsibility for the accuracy, completeness, or usefulness of any information, apparatus, product, or process disciosed, or represents that its use would not infringe privately owned rights. Reference berein to any specific commercial product, process, or service by trade name, trademark, manufacturet, or otherwise does not necessarily constitute or imply its endorsement, recommendation, of favoring by the United States Government or any agency thereof. The views and opinions of authors expressed herein do not necessarily state or reflect those of the United States Government or any agency thereof.

Invited paper to be published in the Proceedings of the International Symposium on Sputtering, Vienna, June 2-6, 1986, (Nucl. Instr. Meth. B). *Work supported by the U. S. Department of Energy, BES-Materials Sclences, under Contract W-31-109-Eng-38. 
BOMBARDMENT-INDULEV SEGREGATION AND REDISTRIBUTION*

\author{
N. Q. Lam and H. Wiedersich \\ Materials Sclence and Technology Division \\ Argonne National Laboratory \\ Argonne, IL 60439 U.S.A.
}

ABSTRACT

During Ion bombardment, a number of processes can alter the compositional distribution and microstructure in near-surface reglons of alloys. The relative 1mportance of each process depends principally on the target composition, temperature, and ion characteristics. In addition to displacement mixing leading to a randomization of atomlc locations, and preferential loss of alloying elements by sputtering, which are dominant at relatively low temperatures, several thermally-activated processes, including radiationenhanced diffusion, radiation-induced segregation and Gibbsian adsorption, also play important roles. At elevated temperatures, nonequilibrium point defects induced by ion impacts become mobile and tend to anneal out by recombination and diffusion to extended sinks, such as dislocations, grain boundaries and free surfaces. The high defect concentrations, far exceeding the thermodynamic equilibrium values, can enhance diffusion-controlled processes, while persistent defect fluxes, originating from the spatial nonuniformity in defect production and annihilation, give rise to local redistribution of alloy constituents because of radiation-induced segregation. Moreover, when the alloy is maintained at high remperature, Gibbsian adsorption, driven by the reductior in free energy of the system, occurs even wthout Irradiation; it involves a compositional perturbation in a few atow layers near the alloy surface. The combination of these processes leads to the complex development of a compositionally-modified layer in the subsurface regfon. Considerable progress has been made recently in identifying and understanding the relative contributions from the individual processes under. various irradiation conditions. In the present paper, selected examples of these different phenomena and their synergistic effects on the evolution of the near-surface compositions of alloys during sputtering and ion implantation at elevated temperatures are discussed.

*Work supported by the U. S. Department of Energy, BES-Materials Sctences, under Contract W-31-109-Eng-38. 


\section{BOMBARDMENT-INDUCED SEGREGATION AND REDISTRIBUTION*}

N. Q. Lam and H. Wiedersich

Materials Science and Technology Division

Argonne National Laboratory

Argonne, IL 60439 U.S.A.

\section{Introduction}

The effect of ion bombardment on the near-surface composition of alloys has created considerable excltement in recent years and become the subject of many detalled Investigations. The current interest in surface compositional modifications by energetic particles was motivated by the importance of this phenomenon in many areas of materials science. These include routine application of Ion sputtering to depth-profile the composition of multicomponent materials, increasing use of ion-beam mixing and ion implantation to tallor new materials with improved hardness, wear, corrosion resistance, caralysis, adhesion and/or reflectance, and concern about plasma contamination in fusion devices by sputtered particles from walls and Iimiters.

Surface composition alterations by preferential sputtering and displacement mfxing near rcom temperature have been observed in many alloy systems. Experimental measurements and understanding of this phenomenon have been reviewed in detail by Andersen [1], Betz [2], Kelly [3,4], and Betz and Wehner [5]. At high temperatures where additional thermally-activated processes are important, the problem of Ion bombardment-induced alloy composition changes becomes more complex $[1,6-14]$. Fcr example, durirg elevated-temperature bombardment, nonequilibrlum point defects induced by ion impacts are mobile and Interact among themselves, wh solute elements and

\footnotetext{
*Work supported by the U. S. Department of Energy, BES-Materials Sclences, under Contract W-31-109-Eng-38.
} 
with extended sinks, such as dislocations, grain boundarles and free surfaces. The high defect concentrations can enhance diffusion-controlled pro-ssses, while persistent defect fluxes, resulting from the spatial nonunfformity in defect production and annihflation, can induce significant redistribution of alloying elements because of radiation-induced segregation. Furthermore, when the alloy is heated to a sufficiently high temperature, Gibbsian adsorption (i.e. thermal segregation of alloy constituents to surfaces and interfaces, driven by the reduction in free energy of the system) occurs even without irradiation. Gibbsian adsorption can be strong and achieves equilibrium more rapidly at higher temperature since diffusion is required. This segregation glves rise to a perturbation in the alloy composition in the outermost atom layers near the surface, and thus affects the boundary conditions of the bombardment-induced surface modification problem. The combination of these processes leads to the complex development of a compositionally-modifled layer, whose thickness and composition depend on bombardment time, the type of alloy, the target temperature, and the species, energy and flux of the Incoming ions. Significant progress has been made over the past five years in identifying and understanding their synergistic effects. The predictions of current models of bombardment-induced surface composition changes are qualitatively in agreement with existing experimental data. Quantitative predictions are still rather uncertain because many of the physical parameters required for the calculations are not well known.

In the present paper, a simple description of the kinetics of the processes involved is given, and selected examples of recent important progress are reviewed. The discussion wlll be linited to elevated-temperature bombardments of metallic alloys, with primary emphaşis placed on 
phenomenological modeling and direct measurements of surface and subsurface compositional changes.

\section{Basic processes}

In order to discuss intelligently the complex interplay of the diverse physical processes in changing alloy subsurface compositions during ion bombardment, elucidated by recent phenomenological model studies and experimental investigations, a brief characterization of the individual processes is presented in this section. We will proceed from the predominantly athermal processes, namely preferential sputcering and displacement minfing, to the thermally-activated processes, including radiation-enhanced diffusion, radiation-induced segregation, and Gibbsian adsorption. Each of these processes has been investigated both experimentally and theoretically with various degrees of sophistication in the past (see, for example, $[1,5,10]$ and references therein). A good physical understanding of them already exists, even though only a limited number of studies has specifically addressed the phenomenon of bombardment-induced surface modifications.

\subsection{Preferential sputtering (PS)}

At frequently used ion energies, 1.e, between $\sim 0.5$ and $500 \mathrm{keV}$, the slowing-down of the incident lons in the target material generates displacement cascades and nonequilibrium point defects (interstitials and vacancies). The cascades are the physical origin of sputtering, when they take place in the vicinity of the surface, Imparting to near-surface atoms sufficlent energy and momentum in the outward direction to overcome their surface binding energy $[14,15]$. There are strong reasons to expect sputtering to be preferential in most alloy systems, on the basis of mass and surface 
binding effects. The former effect results from differences in momentum transfers to atoms of unequal masses. The latter effect arises because the various alloy components, in general, have different surface binding energles, and, hence, require different amounts of energy to escape from the surface. The resulting preferential loss of certain alloying elements by sputtering leads to compositional changes, the spatial extent of which depends on the diffusional processes. Initially, as a consequence of PS, the compositions of the flux of atoms sputtered from the alloy surface and of the bulk are generally quite different. However, after long bombardment times, the steadystate composition of the sputtered-atom flux becomes equal to that of the bulk of a thick target, as dictated by the matter-conservation law. An extensive review of PS effects has been given recently by Betz and Wehner [5]. Using the phenomenological description of PS, we define the total number of $k$-atoms ejected from an alloy target per incident ion, $Y_{k}$, as follows:

$$
Y_{k}=\sum_{n=1}^{\infty} P_{k}^{(n)} C_{k}^{(n)}
$$

where $P_{k}^{(n)}$ is the effective yleld of k-atoms per unit concentration per ton, and $c_{k}^{(n)}$ is the atomic fraction of k-atoms in the nth layer. The distinction between "true" PS or primary effects and secondary effects in alloy sputtering is made explicit in this definition. The factor $\mathrm{P}_{\mathrm{k}}^{(\mathrm{n})}$ contains all the physical variables that are directly related to the individual sputtering events (1.e., the type and energy of the Incident 1on, the type of sputtered atom and Its surface binding energy), whereas secondary effects arising from, e.g., Gibbsian adsorption and radiation-induced segregation influence $Y_{k}$ because they affect the alloy composition in the near-surface region, $c_{k}^{(n)}$. Hence, PS is sald to occur whenever $P_{k}^{(n)} \neq P_{\ell}^{(n)}$ in any nth layer. 
From a practical point of view, the sputtered atoms come predominantly from a rather shallow layer, as shown by Sigmund [14] and in more detall by Falcone and Sigmund [16]. For low-energy sputtering, the contributions decrease approximately exponentially with depth, with a decay length on the order of two atomic layers. Thus, eq. (1) can be replaced by a good approximation:

$$
Y_{k}=P_{k}^{(1)} C_{k}^{(1)}+P_{k}^{(2)} C_{k}^{(2)}
$$

If we define $\gamma$ as the probability for atoms in the second layer to contribute to the sputtered-atom flux, then eq. (2) can be rewritten as

$$
y_{k}=s_{k}\left[(1-\gamma) c_{k}^{(1)}+r c_{k}^{(2)}\right]
$$

with $\mathrm{S}_{\mathrm{k}}$ being the sputtering coefficient of the $k$-component, i.e. the number of $k$-atoms sputtered per incident ion per unit concentration. $s_{k}$ is not necessarily the coefficlent for the pure element and many depend on the alloy composition.

Now, considering a binary alloy $A B$ bombarded by a flux of lons $\phi$ (lons $/ \mathrm{cm}^{2} \mathrm{~s}$ ), the total rate at which atoms of both components are removed per unit area is

$$
\begin{aligned}
\mathrm{dN} / \mathrm{dt} & =\phi\left(\mathrm{Y}_{\mathrm{A}}+\mathrm{Y}_{\mathrm{B}}\right) \\
& =\phi\left\{\mathrm{S}_{A}\left[(1-\gamma) C_{A}^{(1)}+\gamma \mathrm{C}_{A}^{(2)}\right]+\mathrm{S}_{B}\left[(1-\gamma) C_{B}^{(1)}+\gamma C_{B}^{(2)}\right]\right\}
\end{aligned}
$$




$$
\delta \equiv \mathrm{d} \delta / \mathrm{dt}=\Omega \mathrm{dN} / \mathrm{dt}
$$

where $\Omega$ is the average atomic volume and $\delta$ is the total surface displacement, i.e., the thickness of the surface layer removed by sputtering. Note that $\dot{\delta}$ is time dependent because PS, Gibbsian adsorption and radiation-induced segregation make $c_{A}^{(n)}$ and, hence, $c_{B}^{(n)} \equiv 1-c_{A}^{(n)}$ time dependent. Therefore, from a theoretical point of view, $\delta$ and $\mathrm{C}_{A}^{(n)}$ must be calculated in a mutually consistent fashion.

\subsection{Displacement mixing (DM)}

In addition to sputtering atoms from the surface, the displacement cascades also glve rise to DM, which comprises recoll implantation and cascade mixing. Recoll Implantation occurs when the lighter atoms are preferentlally transported In the beam direction due to preferential momentum transfer, whereas cascade mixing is a random-walk process resulting from the movement of higher-order recolls [17-21]. Both recoll implantation and cascade mixing have been observed in recent Investigations of marker-layer shift and broadening during ion bombardment. Generally, the effect of cascade mixing has been found to be much larger than that of recol1 implantation $[18,19,22]$. To a good approximation, DM can be assumed to be temperature independent, since the energies involved in the cascades are substantially greater than thermal energies. The basic aspects of DM have been reviewed recently by Averback [23].

To the degree that the mixing process can be considered as a random walk of atoms, a simplified quantificat $n n$ of DM can be formulated within a diffusion wodel $[17,20,21]$. The displacement-induced diffusion coefficient can be expressed In the well-known form 


$$
D_{k}^{*}=\left\langle R^{2}\right\rangle / 6 t
$$

where $\left\langle\mathrm{R}^{2}\right\rangle$ is the mean square distance an atom has traveled in a time interval $t$, during which it has made $N$ uncorrelated jumps. If we define $\left\langle r^{2}\right\rangle$ as the mean square length of the Individual Jumps, then the coefficient $D_{k}^{*}$ becomes

$$
D_{k}^{*}=\left\langle r^{2}\right\rangle v / 6
$$

with $v \equiv \mathrm{N} / \mathrm{t}$ being the site-exchange frequency. Using a semi-empirical approach, this frequency is related to the defect-production rate $\mathrm{K}$ (displacements per atom per second, dpa/s) by $v=\varepsilon k$, where $\varepsilon$ is the total number of site replacements per displacement (i.e. per Frenkel pair, created). Recent molecular-dynamics calculations indicate that $\varepsilon \simeq 35$ for low primary recoll energies in $\mathrm{Cu}$ [25]. In general, the larger the recoil energy, the higher the value of $\varepsilon$, because the displacement cascades are larger. On the other hand, the mean square jump distance $\left\langle r^{2}\right\rangle$ should be a few times the nearest-neighbor distance $\lambda^{2}$, because a fraction of the atoms w11.1 be relocated by more than a nearest-neighbor distance for larger recoll momenta in off-close-packed directions. Thus, we can write $D_{k}^{*}$ in an approximate form

$$
D_{k}^{*} \simeq \lambda^{2} n K / 6
$$

where $r_{1}$ should be on the order of $10^{2}-10^{3}$. Values of $n$ within this range have been derived from experimental measurements of ion beam mixing [23] and of disordering rates in ordered alloys $[26,27]$ at low temperatures. The net flux of A-atoms across a fixed lattice plane can then be calculated by 


$$
\Omega_{\mathrm{A}}^{*}=-\mathrm{D}_{\mathrm{A}}^{*} \nabla \mathrm{C}_{\mathrm{A}}
$$

It is noted that the product $\eta \mathrm{K}$ and, hence, the effective diffusion coefficient $D_{k}^{*}$ are assumed to be temperature independent, and that replacement collisions are always expected to randomize the alloy system. However, events that take place after the collisional phase of the cascade (1.e., at $\sim 10^{-12}$ ), such as induced defect migration and/or induced recombination are affected by thermodynamic forces. These induced "quasi-thermal" diffusion processes within the cascades may give rise to the frequently observed "chemical" effects in ion-beam mixing, where the chemical affinity and/or heat of mixing can Influence the rate of Intermixing [28-31].

\subsection{Radiation-enhanced diffusion (RED)}

As mentioned above, DM of alloying elements is the dominant atom-transport mechanism during bombardment at low temperatures where vacanctes are imnobile. At elevated temperatures, however, the thermally-activated diffusional process becomes dominant. Generally, between $\sim 0.2$ and $\sim 0.6 \mathrm{~T}_{\mathrm{m}}$ (where $T_{m}$ is the absolute melting point) radiation-induced point defects are mobile, and their concentrations can easily exceed the thermodynamicequilibrium values by several orders of magnitude. Since the total local diffusion coefficients of $A$ and $B$ atoms in the alloy are proportional to the concentrations of vacancies $(v)$ and interstitials $(1), C_{v}$ and $C_{1}, 1 . e$. , $[32,33]$

$$
D_{A}=d_{A v} C_{v}+d_{A i} C_{1}
$$

and

$$
\mathrm{D}_{\mathrm{B}}=\mathrm{d}_{\mathrm{Bv}} \mathrm{C}_{\mathrm{v}}+\mathrm{d}_{\mathrm{Bi}} \mathrm{C}_{i}
$$


diffusion of the alloying elements is strongly enhanced by irradiation. Here, in describing the enhancement of diffusion in a form that can conveniently be extended to the treatment of radiation-induced segregation in the next section, we introduce the diffusivity coefficients $d_{A v}, d_{B v}, d_{A 1}$ and $d_{B 1}$, which contain the kinetic characteristics for diffusion of the elements $A$ and $B$ via vacancies and interstitials, respectively. The coefficients $d_{k j}$ are defined as

$$
d_{k j}=\lambda_{j}^{2} z_{j} v_{k j} / 6
$$

where $\mathrm{k}=\mathrm{A}$ or $\mathrm{B}, \mathrm{j}=1$ or $\mathrm{v}, \lambda_{\mathrm{j}}$ and $\mathrm{Z}_{\mathrm{j}}$ are the elementary jump distance and the coordination number of defect 1 , respectively, and $v_{k j}$ is the effective exchange jump frequency of $a k-j$ pair. It is noted that, even though the diffusivity coefficients are assumed to be spatially independent, the total diffusion coefficients, given by eqs. (10), depend on spatial coordinates via the concentrations of atoms and defects.

At higher temperatures (above $\sim 0.6 \mathrm{~T}_{\mathrm{m}}$ ), the concentration of equilibrium vacancies becomes larger than that of radiation-induced defects and the normal thermal diffusion via vacancy mechanism dominates the atom transport process. Several detailed reviews of the existing theories and experimental measurements of RED have been published over the past decade [34-37].

\subsection{Radiation-induced segregation (RIS)}

Concurrently with RED, RIS takes place in the alloy during irradiation, because the same defects that are responsible for RED can also induce segregation of alloying elements. The physical origin for RIS is as follows. At sufficiently high temperatures, those mobile point defects that escape mutual recombination anneal out by diffusion to extended sinks. Since 
the defect fluxes are always associated with fluxes or atoms, any preferential association of defects with a particular alloy component and/or preferential participation of a compcnent in defect diffusion will colple a net flux of the alloying element to the defect fluxes. This preferential defeat-solute flux coupling will lead to a spatial redistribution of the alloy composition during 1rradiation. Thus, RIS can produce concentration gradients in initially homogeneous alloys even in the absence of PS and/or Gibbsian aisorption. Model descriptions of RIS in dilute alloys [38], concentrated binary [32] and ternary [39] alloys are available, and extensive reviews of RIS and its effects on alloy microstructure have been published recently $[33,40,41]$.

A simple treatment of RIS, proposed by Wiedersich et al. [32], 1s based on the concept of partitioning the defect fluxes into those occurring by exchange with the various alloy components, and the atom fluxes into those taking place via vacancies and interstitials. In a binary alloy $A B$, for example, the fluxes of atoms and defects with respect to a coordinate system fixed on the crystal lattice can thus be expressed in terms of concentration gradients, and partial and total diffusion coefficients of all the species present:

$$
\begin{aligned}
& \Omega J_{\mathrm{v}}=\left(\mathrm{d}_{\mathrm{Av}}-\mathrm{d}_{\mathrm{Bv}}\right) \mathrm{C}_{\mathrm{v}} \alpha \nabla \mathrm{C}_{\mathrm{A}}-\mathrm{D}_{\mathrm{v}} \mathrm{VC}_{\mathrm{v}} \text {, } \\
& \mathrm{NJ}_{1}=-\left(\mathrm{d}_{\mathrm{Ai}}-\mathrm{d}_{\mathrm{Bi}}\right) \mathrm{C}_{1} \alpha \nabla \mathrm{C}_{\mathrm{A}}-\mathrm{D}_{1} \mathrm{VC}_{1} \text {, } \\
& \Omega J_{A}=-D_{\dot{A}} \alpha \nabla C_{A}-C_{A}\left(d_{A I} \nabla C_{1}-d_{A v} \nabla C_{v}\right) \text { 。 }
\end{aligned}
$$

and

$$
\Omega J_{B}=-D_{B} a \nabla C_{B}-C_{B}\left(d_{B I} \nabla C_{1}-d_{B v} \nabla C\right. \text { v }
$$

Bise, $\alpha$ is the thermodynamic factor which is related to the activity coefficlents of the alloy components and differs from untty when the alloy is no longer ideal, and $D_{V}, D_{1}$, and $D_{A}$ and $D_{B}$ (already defined in eqs. (10)) are 
the total diffusion coefficlents of the defects and alloy consituents, respectively, whish can be described in the general form

$$
D_{j}=\sum_{k} d_{k j} C_{k} \quad(j=1, v \text { and } k=A, B)
$$

and

$$
D_{k}=\sum_{j} d_{k j} C_{j},
$$

with $d_{k j}$ belng given by eq. (11). These coefficients are spatially dependent. As expressed in eqs. (12), the defect fluxes are driven by the Aand B-atom concentration gradients as well as by thelr own concentration gradients. Similarly, the atori fluxes are induced by both the defect concentration gradients and the atom chemical-potential gradients. The first terms on the right-hand side of eqs. (12a) and (12b) represent the KIrkenda11 effects from the vacancy and interstitial diffusion mechanisms, respectively. These terms have opposite signs simply because the interstitial flux Induces an atom flux in the same direction, whereas the vacancy flux generates a flux of atoms in the opposite direction.

Some predictions can be derlved from the flux equations, eqs. (12), for the segregation trends, by assuming that quasi-steady state with respect to the defect buildup has been achleved. At quasi-steady state, $J_{v}=J_{1}$, the total flux of A atoms is given by [33]

$$
J_{A}=-\bar{D} \nabla C_{A}-\bar{D}\left(\frac{d_{A t}}{d_{B 1}}-\frac{d_{A v}}{d_{B v}}\right) \nabla C_{d}
$$

where the subscript " $d$ " denotes either vacancy or interstitial, $\bar{D}=\left(d_{A v} C_{A} D_{B}+d_{B v} C_{B} D_{A}\right) /\left(d_{A v} C_{A}+d_{B v} C_{B}\right)$, and $\hat{D}=\left(d_{B v} d_{B 1} C_{A} D_{B}\right) /\left(d_{A v} C_{A}+d_{B v} C_{B}\right)$. At short itradiation times, the concentration gradient $V C_{A}$ in an inftially 
homogeneous alloy is rather small; therefore, the direction and magnitude of $J_{A}$ are controlled by the last term in eq. (14). For example, the net flux of A atoms will be in the same direction as the defect fluxes if $\mathrm{d}_{\mathrm{Ai}} / \mathrm{d}_{\mathrm{BI}}>$ $\mathrm{d}_{\mathrm{Av}} / \mathrm{d}_{\mathrm{Bv}}$ or $v_{\mathrm{Ai}} / v_{\mathrm{BI}}>v_{\mathrm{Av}} / v_{\mathrm{Bv}}$ via eq. (11). In this case, the A component will be enriched in any region where there is an influx of defects. On the contrary, if $v_{\mathrm{A} 1} / v_{\mathrm{B} 1}<v_{\mathrm{Av}} / v_{\mathrm{Bv}}$, the net A-atom flux w1ll occur in the direction opposite to the defect fluxes, and the element $A$ will be depleted in regions where an influx of defects exists. It is noted that the magnitude of $\mathrm{J}_{\mathrm{A}}$ will be maximum when $\mathrm{A}$ atoms migrate exclusively via an interstitial mechanism and $B$ atoms via vacancies.

If the defects - either vacancies ir interstitlals - interact strongly with a particular alloy component, say A atoms, to form tightly-bound, but mobile, atom-defect complexes, then the net flux of $A$ atous and the defect fluxes will also be in the same direction. Any preferential participation of A atoms in the interstitial population can be accounted for by incorporating inco the diffusivity coefficients $d_{A 1}$ and $d_{B i}$ [eq. (11)] factors that represent the nonrandom occupation of literstitials by $A$ and $B$ atoms:

$$
C_{1 A}=C_{i} C_{A} \exp \left(H_{1 A}^{b} / k T\right) /\left[C_{A} \exp \left(H_{1 A}^{b} / k T\right)+C_{B}\right]
$$

and

$$
C_{1 B}=C_{1} C_{B} /\left[C_{A} \exp \left(H_{1 A}^{b} / k T\right)+C_{B}\right]
$$

where $k$ is the Boltzmann constant, $T$ is the absolute temperature, and $\mathrm{H}_{1 \mathrm{~A}}^{\mathrm{b}}$ is the effective A-interstitial binding energy.

On the other hand, in order to account for atom transport by tightlybound, mobile A atom-vacancy (vA) complexes in dilute alloys, additional terms derived from the contribution of the complex flux $J_{v A}=-D_{v A} \nabla C$ mast be 
Included in eqs. ( $12 a, c$ and $d$ ) for $J_{v}, J_{A}$ and $J_{B}$ :

$$
\begin{aligned}
\Omega_{v}= & {\left[\left(d_{A v}-d_{B v}\right) a-K_{v A} D_{v A}\right] C_{v} \nabla C_{A} } \\
& -\left(D_{v}+K_{v A} D_{v A} C_{A}\right) \nabla C \\
\Omega_{A}= & -\left[a D_{A}+\left(1-2 C_{A}\right) K_{v A} D_{v A} C_{v}\right] \nabla C_{A} \\
& -d_{A i} C_{A} \nabla C_{1}+C_{A}\left[d_{A v}-\left(1-2 C_{A}\right) K_{v A} D_{v A}\right] \nabla C_{v}
\end{aligned}
$$

and

$$
\begin{aligned}
\Omega J_{B}= & -\left[\alpha D_{B}+2 C_{B} K_{v A} D_{v A} C_{v}\right] \nabla C_{B} \\
& -d_{B 1} C_{B} \nabla C_{1}+C_{B}\left[d_{B v}+2 C_{B} K_{v A} D_{v A}\right] C_{v},
\end{aligned}
$$

where $D_{v A}$ is the diffusion coefficient of the vA complex, $D_{v A}=\lambda^{2} v_{v A} / 6\left(v_{v A}\right.$ being the complex jump frequency), and $\mathrm{K}_{\mathrm{vA}}$ is the rate constant for the formation of $\mathrm{VA}$ complexes in equilibrium, $\mathrm{K}_{\mathrm{VA}}=12 \exp \left(\mathrm{H}_{\mathrm{VA}}^{\mathrm{b}} / \mathrm{kT}\right)\left(\mathrm{H}_{\mathrm{VA}}^{\mathrm{b}}\right.$ is the complex binding energy). It should be pointed out that for concentrated alloys, atom transpori by tight $1 y$-bound vacancy-solute complexes is unimportant, and eqs. (12) are applicable.

\subsection{Gibbsian adsorption (GA)}

When the alloy sysizm evolves towards equilibrium, a thermodynamic driving force gives rise to elther enrichment or depletion of the A component at the surface, depending on whether the heat of absorption for the element $A$ is negative or positive [42]. This thermal-segregation phenomenon is known as GA, which tends to minimlze the surface free energy. In the absence of sputtering, GA achleves equilibrium after a certain time which is mainly contrulled by the temperature. The higher the temperature, the shorter this time 1s. At equilibrium, the atom fraztions of A and B in the "surface phase" (assumed to be confined to the outaznost atom layer), $C_{A}^{(1)}$ and $C_{B}^{(1)}$, are related to the respective atom fractions in the "bulk phase", $C_{A}^{b}$ and $C_{B}^{b}$, by 
the relationship [42]

$$
c_{A}^{(1)} / C_{B}^{(1)}=\left(c_{A}^{b} / C_{B}^{b}\right) \exp \left(-\Delta G_{a} / k T\right)
$$

where $\Delta G_{a}=\Delta H_{a}-T \Delta S_{a}$ is the GA free energy, with $\Delta S_{a}$ and $\Delta H_{a}$ being the entropy and enthalpy (or heat) of adsorption for the $A$ component, respectively.

During the concentration bulldup towards equilibrium, the net flux of $A$ atoms Into the surface atomic plane, $J_{A}$, is calculated by

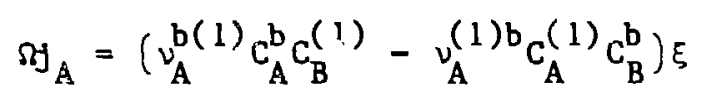

where $\xi$ is the atomic layer thickness, and the surface-to-bulk jump frequency $v_{A}^{(1) b}$ is related to the bulk-to-surface jump frequency $v_{A}^{b}(1)$ by the following equation derived from the condition of equilibrium $\left(j_{A}=0\right)$

$$
\nu_{A}^{(1) b}=\nu_{A}^{b(1)} \exp \left(\Delta G_{a} / k T\right)
$$

Since $\nu_{A}^{b(1)}$ is a function of jump frequencies and "bulk" concentrations of defects,

$$
v_{A}^{b(1)}=v_{A v} C_{v}^{b}+v_{A 1} C_{i}^{b}
$$

GA can be strongly enhanced by irradiation at temperatures below $\sim 0.6 T_{m}$ * Furthermore, since GA involves a perturbation of the alloy composition in one or two atomic layers near the surface, 1.e. to a depth comparable to the sputter depth [16], the extraction of Information about PS from measurements 
of surface compositional changes requires a good understanding of the Interplay of these GA and PS processes.

Equation (17) Indicates that the plot of $\ln \left[\mathrm{C}_{A}^{(1)} / C_{B}^{(1)}\right]$ versus $1 / T$ is a stralght line, whose slope and intercept are related to $\Delta \mathrm{H}_{\mathrm{a}}$ and $\Delta \mathrm{S}_{\mathrm{a}}$. The temperature dependence of GA has been measured recently on a number of alloys $[11,12,43,44]$ using 1 on scattering spectroscopy (ISS), which is a technique extremely sensitive to the first surface atom layer. Some typical results are presented in $\mathrm{fig} .1$ for $\mathrm{NI}-\mathrm{Cu}$ and $\mathrm{Ni}$-Au alloys $[11,12]$. The values of $\Delta \mathrm{H}_{\mathrm{a}}$ and $\Delta S_{a}$ deduced are tabulated in table 1 , together with the data obtained recently for a N1-9.5 at.\% S1 alloy [44]. The ISS technique was first employed to demonstrate $\mathrm{GA}$ of $\mathrm{Cu}$ in the $\mathrm{NI}$-Cu system by Brongersma et al. $[45,46]$. Other analytical techniques such as Auger electron spectroscopy (AES) [47-50] and time-of-flight atom-probe fleld-ion mlcroscope (FIM) [51-53] were also used to study GA. Unfortunately, owing to the finite escape depth of the Auger electrons, AES cannot yleld definitive information on the composition in the outermost atom layer. The FIM technique, on the other hand, provides information about the first suríace layer composition; however, FIM measurements can easily be affected by thermal segregarion of interstitial impurities, such as $S$ and $P$, since it is difficult to subject the fleld emission tip of the alloy specimens used to "cleaning" treatments by intermittent sputterings at high temperatures [54].

\section{Compositional redistribution in alloys during inert-gas inn sputtering} 3.1 Theoretical modeling

Taking into account the effects of all the processes described above, we can cast the bombardment-induced composition modification phenomenon into a phenomenological model by formulating the following set of coupled partial 
differential equations describing the temporal and spatial evolution of defect and atom concentrations

$$
\begin{aligned}
& \partial C_{v} / \partial t=-\nabla \cdot J_{v}+K-R \\
& \partial C_{1} / \partial t=-\nabla \cdot J_{1}+K-R
\end{aligned}
$$

and

$$
\partial C_{A} / \partial t=-\nabla \cdot\left(J_{A}+J_{A}^{*}\right)
$$

where $R$ is the total local rate of defect losses by recombination and annihilation at internal sinks. The equation for the $B$ component is not needed because $C_{B}=1-C_{A}$. The accumulation of incident chemlcally-inactive Ions is neglected.

The time-dependent defect and atom distributions can be determined by solving eq̣s. (21) numerically for appropriate inttial and boundary conditions. For the semi-infinite geometry with a moving boundary, the sputtered surface can be mathematically tmmobilized by the transformation $z=1-\exp [-\beta(x-\delta)]$ of the physical space $\delta<x<\infty$ to a reduced space $0<z<1[6,55]$, with $B$ being a scaling factor. The inclusion of GA in the model requires, however, that the first two atomic layers be treated in a discrete fashion [9]. Below the second layer, the evolution of concentrations In time and space are calculated using a continuum formalism $[6,55]$.

Model calculations have been carried out to predict the dependence of surface and subsurface compositions of bombarded alloys on several material and Irradiation vartables, as well as to fit and Incerpret experimental measurements. Although the effects of each individual process or of a combination of processes or the compositional modification in model alloys can be studied In detall $[8,9,56]$, because the present phenomenological approach 
permits straightforward varlation of the primary physical parameters, a quantitative comparison of theoretical calculations with experiments is difficult at present, since many of these parameters are st111 virtually unknown, especially for alloys $[11,12,44,57,58]$. For this reason, in order to fit the experimental measurements, a large number of calculations must be performed using various combinations of physical parameters. Semiquantitative modeling of bombardment-induced compositional redistributions in $\mathrm{NI}-\mathrm{Cu}$ [11], $\mathrm{NI-Au}$ [12] and $\mathrm{N}-\mathrm{Si}$ [44] alloys undergoing 3-keV $\mathrm{Ne}^{+}$sputtering has been undertaken recently. Some selected examples are shown in the following for a $\mathrm{N} 1-40$ at.\% $\mathrm{Cu}$ alloy. In the calculations, the energles of vacancy migration via $\mathrm{N} 1$ and $\mathrm{Cu}$ atoms were taken to be within the ranges $\mathrm{H}_{\mathrm{NI}-\mathrm{V}}^{\mathrm{m}}=0.95-1.0 \mathrm{eV}$ and $\mathrm{H}_{\mathrm{Cu}-\mathrm{m}}^{\mathrm{m}}=0.93-0.99 \mathrm{eV}$, respectively, consistent with the estimate for the effective vacancy migration energy in a $\mathrm{NI}-40$ at.\% Cu alloy $(\sim 0.96 \mathrm{eV})$ obtalned by Iinear interpolation of the energies for pure $\mathrm{NI}$ and $\mathrm{Cu}$. Here, $\mathrm{H}_{\mathrm{Cu}-\mathrm{m}}^{\mathrm{m}}$ was assumed to be smaller than $\mathrm{H}_{\mathrm{N} 1-\mathrm{m}}^{\mathrm{m}}$ (by $\sim 0.02 \mathrm{eV}$ ), based on the previous observation that $\mathrm{Cu}$ solutes are depleted at (1.e., they segregate away from) the Irradiated surface [40]. The lnterstitial migration energy was taken to be $0.15 \mathrm{eV}$, the same for both alloying elements. Point defects were allowed to annihilate at internal sinks, which were assumed to be radiation-induced dislocations whose spatial distribution was identical to that of the damage rate $K$. The peak density was allowed to bulld up linearly with time, reaching a saturation level $\rho^{\max }$ at a time $t^{*}$;

$$
\rho(\text { at danage peak })= \begin{cases}\rho_{0}+\left(\rho^{\max }-\rho_{0}\right) t t^{*} & \text { for } t<t^{*} \\ \rho^{\max } & \text { for } t>t^{*}\end{cases}
$$


where $\rho_{0}$ is the density of Intrinstc dislocations, taken to be $10^{7}$ dislocations $/ \mathrm{cm}^{2}$. The density $\rho^{\max }$ and time $t^{*}$ were assumed to be $10^{10}$ dislocations $/ \mathrm{cm}^{2}$ and $10^{2} \mathrm{~s}$, respectively. The GA entropy and enthalpy for $\mathrm{Cu}$ were measured experimentally (11sted in table 1).

The calculated spatial distribution of $\mathrm{Cu}$ atoms during $3-\mathrm{keV} \mathrm{Ne}^{+}$ sputtering at $500^{\circ} \mathrm{C}$ is 11 lustrated in $\mathrm{f} f \mathrm{~g} .2$ for a number of sputtering times. The spatially-dependent damage rate $k$, normalized to its maximum value, is shown by the dashed curve in the top illustration $(t=0)$. The effective rate $K$ was deduced from the theoretical damage rate $K_{0}$, calculated using the TRIM code [59] with a displacement energy of $30 \mathrm{eV}$, by $\mathrm{K}=\varepsilon \mathrm{K}_{\mathrm{o}}$. Here, the defect-froduction efficiency $\varepsilon$ was estimated to be $\sim 0.4$ [60]. The peak damage occurs at $\sim 1 \mathrm{~nm}$ and the total range is $\sim 7 \mathrm{~nm}$. With an fon flux of $3.75 \times 10^{13}$ tons $/ \mathrm{cm}^{2} \mathrm{~s}$ used in the calculations and experiment (see section 3.2), the calculated peak-damage rate was $\mathrm{K}_{\mathrm{O}}^{\max }=3.5 \times 10^{-2} \mathrm{dpa} / \mathrm{s}$. Because a logarithmic scale is used for the distance axis to 1llustrate rapid compositional variations near the surface and moderate ones at greater depths, the composition of the first atomic layer, $0.206 \mathrm{~nm}$ thick, is shown in steplike form. The thickness of the surface layer removed by sputtering is indicated for various times. Since the initial starting conditions correspond to the thermodynamic equilibrlum state of the alloy, with an equilibrated Cu enrichment (due to $\mathrm{GA}$ ) at the surface, the Cu surface concentration, $\mathrm{C}_{\mathrm{Cu}}^{(1)}$ is very high initially, then decreases with sputtering time, and finally attalns a steady-state value after $\sim 10^{4} \mathrm{~s}$. The thickness of the compositionallyaltered layer at $500^{\circ} \mathrm{C}$ is already noticeably larger than the damage range.

The temperature dependence of the bombardment-induced compositional changes, as reflected by both the time evolution of $\mathrm{C}_{\mathrm{Cu}}^{(1)}$ and steady-state concentration profiles, is shown in fig. 3. Two sets of initial conditions 
were used: (1) thermodynamic equilibrium state of the alloy, with $\mathrm{Cu} G A$ at the surface, and (11) uniform composition of the alloy up to the surface (1.e., it was assumed that the alloy was brought to temperature and sputtered instantaneously). However, regardiess of the inftial starting conditions, the steady-state surface and subsurface compositions are unique for a given temperature. As seen in fig. $3 \mathrm{~A}$, at short sputtering izües, $t \leq 10 \mathrm{~s}, \mathrm{GA}$ controls the magnitude of $\mathrm{C}_{\mathrm{Cu}}^{(1)}$; when starting from the equilibrium state, $\mathrm{C}_{\mathrm{Cu}}^{(1)}$ is nearly 100 at. ${ }^{2}$. with increasing time, however, PS and RIS lead to a sradual decrease in $\mathrm{C}_{\mathrm{Cu}}^{(1)}$ towards a steady-gtate value given by

$$
\frac{s_{C u}\left[(1-\gamma) c_{C u}^{(1)}+r c_{C u}^{(2)}\right]}{s_{N i}\left[(1-\gamma) c_{N i}^{(1)}+r c_{N i}^{(2)}\right]}=\frac{c_{C u}^{b}}{c_{N 1}^{b}}
$$

At steady state, the surface alloy composition, $\mathrm{C}_{\mathrm{Cu}}^{(1)} / \mathrm{C}_{\mathrm{N} i}^{(1)}$, is thus determined by the partial sputtering coefficients, the contribution of the second layer to the sputtered-atom flux, $Y$, and the bulk composition, in such a way that the compositions of the sputtered-atom flux and the bulk alloy become equal. The temperature dependence of steady-state $\mathrm{C}_{\mathrm{Cu}}^{(1)}$ is connected with the magnitude of $Y[11]$. The results plotted in fig. $3 \mathrm{~A}$ were obtained for $\gamma=0.35$. We will discuss further the effect of $Y$ in the next section, in conjunction with the interpretation of experimental measurements.

Figure 3B shows the steady-state concentration profiles in the subsurface region calculated for various temperatures. The values of $\mathrm{C}_{\mathrm{Cu}}^{(1)}$ and $\mathrm{C}_{\mathrm{Cu}}^{(2)}$ are clearly indicated, using a logarithmic scale for the depth. Near room temperature, where point-defect mobility is limited, PS and DM are the main processes that govern the development of the alloy composition in the altered layer, which extends to a depth approximately equal to the damage range. The 
additional effect of $\mathrm{GA}$, which is quite small at this temperature, $1 \mathrm{~s}$ reflected by the noticeable difference between $\mathrm{C}_{\mathrm{Cu}}^{(1)}$ and $\mathrm{C}_{\mathrm{Cu}}^{(2)}$. Above $\sim 100^{\circ} \mathrm{C}$, GA, RED and RIS become significant, and effectively determine the extend of, and the composition in, the altered layer. The higher the temperature, the thicker the altered layer. At $700^{\circ} \mathrm{C}$, for example, the thickness of this layer is $\sim 2 \mathrm{Im}$, which is $\sim 300$ times larger than the damage range. Compositional changes at such large depths suggest that the effects of RED and RIS are profound at elevated temperatures. The long times which are necessary to achieve steady state at high temperatures derive from the extension of the concentration gradient to such depths.

\subsection{Experimental observations}

The first study of high-temperature ion bombardment-induced surface composition changes was carried out ten years ago by H. Snimizu et al. [61] on Ni-Cu alloys using AES. They observed a strong effect of sputtering temperature on the near-surface composition in the temperature range from 100 to $600^{\circ} \mathrm{C}$. However, since the compositional changes were not measured in situ during sputtering, the interpretation of their results was complicated by secondary effects noticed during cooling of the sputtered specimen to the temperature where AES was performed. Their observations have, nevertheless, indicated the Importance of thermally-activated processes in sputter-induced composition alterations.

In situ AES measurements of near-surface compositional changes in a $\mathrm{Cu}-40$ at.\% $\mathrm{Ni}$ alloy during $5-\mathrm{keV} \mathrm{Ar}^{+}$sputtering at elevated temperatures were made by Rehn et al. $[7,62]$. Two pairs of Auger transitions were used: Ni transitions at 102 and $716 \mathrm{eV}$, and $\mathrm{Cu}$ transitions at 106 and $320 \mathrm{eV}$. The lowenergy Auger electrons are more sensitive to near-surface composition changes (In the first two atom layers), whereas the higher-energy electrons contain 
Information about the composition further below the surface (within a depth of $\sim 1.3 \mathrm{~nm})$. These measurements revealed that the $\mathrm{Cu}$ depletion in the deeper subsurface region, which increased steadily with temperature from 300 through $600^{\circ} \mathrm{C}$, significantly exceeded that in the first two surface layers. This was explained in terms of strong GA of $\mathrm{Cu}$ playing an important role in the formation of the altered layer. The time required to achleve steady state in the near-surface region was found to increase rapidly with increasing temperature. Steady-state concentration profiles were also measured after rapid specimen cooling to room temperature. They indicated that deviations from the bulk composition occurred up to depths of $\sim 1$ and 3 in in the specimens sputtered at 500 and $600^{\circ} \mathrm{C}$, respectively.

Swartzfager et al s [63] performed a similar study on Cu-Ni, Ag-Au and AllPd alloys using ISS, which is a surface layer-sensitive technique. The alloys were sputtered with $2-\mathrm{keV} \mathrm{Ne}{ }^{+}$Ions at temperatures between 200 and $550^{\circ} \mathrm{C}$, and the compositional changes in the outermost atom layer were probed in situ with the same lons. Steady-state concentration profiles were measured after sample quenching to ambient temperature. Similar to AES studies, it was found that the altered-layer thickness increased rapidly with temperature above $\sim 400^{\circ} \mathrm{C}$. With the aid of a theoretical model formulated by Ho [64], which includes only PS and RED, the steady-state concentration proifles were analyzed in order to obtain Information about RED in the bombarded alloy. The RED coefficients were found to be between $10^{-16}$ and $10^{-15} \mathrm{~cm}^{2} / \mathrm{s}$, virtually independent of temperature below $-400^{\circ} \mathrm{C}$, indicating that in this regime the defects annihilate predominantly at fixed sinks. The time evolutior of the alloy composition in the first atom layer during bombardment was unfortunately not measured. 
A systematic ISS study of low-energy fon bombardment-induced composition modifications in $\mathrm{Ni}-\mathrm{Cu}$ alloys was carried out by Lam et al. [11]. Both the compositional changes in the outermost atom layer during sputtering and steady-state concentration profiles were measured. Their results are shown in fIgs. 4 and 5, where the evolution of the Cu/Ni ISS ratio measured on a Ni-40 at.\% $\mathrm{Cu}$ alloy during $3-\mathrm{keV} \mathrm{Ne}^{+}$sputtering (with a flux of $3.75 \times 10^{13}$ lons $/ \mathrm{cm}^{2} \mathrm{~s}$ ) at temperatures and during depth-profiling at room temperature is plotted. Longer times were required to reach steady state at higher temperatures because of the rapidly-increasing thicknesses of the altered layers. These measur ments were in good agreement with other studies discussed above, and could be semi-quantitatively fitted by the results of theoretical modeling described in section 3.1. However, Lam et al. observed that the steady-state $\mathrm{C}_{\mathrm{Cu}}^{(1)}$ was noticeably temperature dependent during sputtering above $-400^{\circ} \mathrm{C}$. This was in contrast to previous theoretical predictions, which were based on the assumption that sputtered atoms orfginated entirely from the first atomic layer $[6,8,9]$. The observed gradual increase of the steady state $\mathrm{C}_{\mathrm{Cu}}^{(1)}$ (larger than $\mathrm{C}_{\mathrm{Cu}}^{\mathrm{b}}$ ) with temperature cannot be explatned in terms of the temperature dependence of the sputtering coefficients in a reasonable way, because it would require that (1) the partial sputtering coefficients we strongly temperature dependent, and ( $1 \dot{i}) \mathrm{N} 1$ atoms becnme preferentially sputtered at high temperatures. It is unlikely that these requirements can be fulfilled because both the sputtering coefficients and sputtering preference in alloys should not be significantly cemperature dependent below $\sim 0.7 \mathrm{~T}_{\mathrm{m}}$ in view of the temperature-independent coefficients found for pure metals sputtered by chemica 1 y-inactive fons at these temperatures [65]. In addition, the sputtering coefficients have also been found to be composition independent for $\mathrm{NI}-\mathrm{Cu}$ alloys [66]. These 
arguments led Lam et al. to interpret the temperature dependence of $\mathrm{C}_{\mathrm{Cu}}^{(1)}$ in terms of significant contributions to the sputtered-atom flux from subsurfare layers, predominantly from the second layer. GA tends to increase the $\mathrm{Cu}$ concentration in the first atomic layer relative to that in the subsurface layers, as the rate of atom exchange between these layers increases with increasing temperature. The steady-state condition [eq. (22)] can be met with an increased $\mathrm{C}_{\mathrm{Cu}}^{(1)}$, if this increase is balanced by a corresponding decrease in $\mathrm{C}_{\mathrm{Cu}}^{(2)}$. That is, a sufficient fraction of the sputtered-atom flux originates from the second layer. By comparing detalled model calculations (discussed in section 3.1) with experimental observations, Lam et al. suggested that this fractiun was $\gamma \simeq 0.35$ [11]. This value of $\gamma$ is, even though on the high side, consistent with recent estimates of the characteristic depth of sputtering by Kelly and Oliva [67]. Substantlal Cu depletion in the second and deeper layers in $\mathrm{Ni}-\mathrm{Cu}$ alloys bombarded at elevated temperatures has been found in both theoretical calculations $[8,9,11]$ and experiments (see fig. 5, as well as $[7,63])$. Similar steep concentration gradients have also been ohserved by Andersen et al. [68], who used measurements of the temperature dependence of the angular distribution of material sputtered from a $\mathrm{Pt}-\mathrm{Cu}$ alloy to show that during fon bombardment the outermost atom layer is enriched with $\mathrm{Cu}$, a component that is known to Gibbsian-adsorb.

Lam et al. have also deduced the RED coefficierts from the measured concentration profiles, using Ho's equation describing the alloy composition in the altered layer at steady state [64]. Their results were in good agreement with ISS dati of Swartzfager et al. [63] and consistent with AES measurements of Shimizu et al. [69] and Rehn et al. [57]. These RED studies clearly demonstrate that point defects produced in the near-surface region during fon sputtering at elevated temperatures migrate well into the sample 
interior. Since the same defects which are responsible for RED can also produce RIS, some contribution of RIS to compositional changes in the deeper region far from the surface is expected. Such contribution was measured recently $[57]$.

\section{Implant redistribution in metals during ion implantation}

The same processes that are operative during inert-gas ion sputtering of alloys also occur during ion implantation of metals. However, in the Implantation case, the fucomfing lons are incorporated into the host metal matrix to create a new alloy; the solute (or implant) concentration is thus time dependent. Once becoming a new component of the alloy system, the Implant is subjected to sputtering and redistribution caused by the operation of the processes described above.

A kinetia model has been developed recently by Lam and Leaf [55] to Investigate the synergistic effects of these processes on the spatial redistribution of implanted atoms during implantation. The effects of spatially-nonuniform rates of damage and Ion deposition, as well as the movement of the bombarded surface as a result of sputtering and introduction of foreign atoms into the system, were taken into account. The evolution of implant concentration profile in time and space was calculated for various temperatures, ion energies, and ion-target combinations. The results of this work are useful in elucidating the essential physics of the elevatedtemperature ion implantation process.

We consider a metal substrate $B$ into which A atoms are implanted at a flux ф. A number of A atoms will end up in interstitial sites, and the rest in substitutional sites of the host lattice. The respective rates of implantation into these sites are $\mathrm{f}_{1} \phi$ and $\mathrm{f}_{\mathrm{S}} \phi$ (atom fraction/s). During 
Implantation, point defects are created by ion Impact at a rate $K$

$(\mathrm{dpa} / \mathrm{s})$. Since the interstitial defects are distinguishable by atom species (in contrast to vacancles), the rate of interstitial production is partitioned into $\mathrm{KC}_{\mathrm{A}}$ and $\mathrm{KC}_{\mathrm{B}} \equiv \mathrm{K}\left(1-\mathrm{C}_{\mathrm{A}}\right)$ for $\mathrm{A}$ - and $\mathrm{B}$-interstitials, respectIvely, with $C_{A}$ and $C_{B}$ being the respectlve local concentrations of $A$ and $B$ atoms in substitution. The Interstitials and vacancies annihilate by mutual recombination and/or diffusion to defect sinks. Iu addition, vacancles and B-interstitials can interact with free solute atoms, giving rise to the formation of vacancy-solute complexes and conversion of Binterstitials to A-interstitials, respectively.

The local concentrations of vacancies (v), B-interstitials (iB), Ainterstitials (iA), A-vacancy complexes (vA) and free substitutional solutes (A) change with implantation time according to the following system of kinetic equations:

$$
\begin{aligned}
& \partial \mathrm{C}_{\mathrm{v}} / \partial \mathrm{t}=-\nabla \cdot \mathrm{J}_{\mathrm{v}} \quad+\mathrm{F} \quad-\mathrm{f}_{\mathbf{s}} \phi+\mathrm{F}_{\mathrm{v}} \\
& \partial C_{i B} / \partial t=-\nabla \cdot J_{i} r+K\left(1-C_{A}\right) \quad+F_{i B} \\
& \partial C_{i A} / \partial t=-\nabla \cdot J_{i A}+K_{A}+f_{i} \phi+F_{i A} \\
& \partial \mathrm{C}_{\mathrm{vA}} / \partial \mathrm{t}=-\nabla \cdot \mathrm{J}_{\mathrm{vA}}+\mathrm{F}_{\mathrm{vA}} \\
& \partial C_{A} / \partial t=-\nabla \cdot J_{A} \quad-K_{A}+f_{S} \phi+F_{A}
\end{aligned}
$$

where the F's denote the local rates of creation and loss of species by chemical-type reactions (1.e. formation and dissociation of defect-solute complexes, and defect recombination and annihilation), and the J's are the fluxes of the mobile spectes, defined as [38]:

$$
\begin{aligned}
& \mathrm{J}_{\mathrm{v}}=-\left(1+\sigma_{\mathrm{v}} \mathrm{C}_{\mathrm{A}}\right) \mathrm{D}_{\mathrm{v}} \nabla \mathrm{C}_{\mathrm{v}} \\
& J_{i B}=-\left(1+\sigma_{1} C_{A}\right) D_{i B} \nabla C_{i B} \\
& J_{i A}=-D_{i A} \nabla C_{1 A} \\
& \mathrm{JvA}_{\mathrm{A}}=-\mathrm{D}_{\mathrm{vA}} \nabla \mathrm{C}_{\mathrm{vA}} \\
& \mathrm{J}_{\mathrm{A}}=-\sigma_{1} C_{A} D_{i B} \nabla C_{1 B}+\sigma_{v} C_{A} D_{v} \nabla C_{v} \text {. }
\end{aligned}
$$


Here, $D_{v}, D_{i B}, D_{i A}$ and $D_{v A}$ are the diffuston coeffictents of defects and defect-solute complexes. The constants $\sigma_{v}$ and $\sigma_{1}$ are the capture factors for vacancy-solute and interstitial-solute encounters. For strong defectsolute binding, $\sigma_{v}=6$ and $\sigma_{1}=6$, and for repulsion or no interaction, $\sigma_{v}=2$ and $\sigma_{1}=0[38,70]$. The free solute flux artses from the coupling of A atoms with free B-interstitial and vacancy fluxes.

Concurrently with the bulldup of solute concentration in the host matrix, the surface is subjected to displacements, due to the introduction of forelgn atoms into the system and sputtering. The former gives rise to surface relaxation in the - $x$ direction, at a rate $\delta_{-}$, whereas the latter causes surface recession in the $+x$ direction, at a rate $\delta_{+}$. The rate $\delta_{\text {_ }}$ can be calculated from the net atom flux towards the surface:

$$
\delta_{-}=J_{1 A}+J_{1 B}-J_{v}-J_{v A},
$$

while the rate $\dot{\delta}_{t}$ is determined by the fon flux, the partial sputtering coefficients, $S_{A}$ and $S_{B}$, and the surface concentrations of $A$ and $B$ atoms:

$$
\delta_{+}=\phi \Omega\left[\mathrm{S}_{\mathrm{A}} \mathrm{C}_{\mathrm{A}}^{(1)}+\mathrm{S}_{\mathrm{B}}\left(1-\mathrm{C}_{\mathrm{A}}^{(1)}\right)\right]
$$

where the concentration of the second layer to the sputtered-atom flux is neglected. The net surface displacement rate,

$$
\dot{\delta} \equiv \mathrm{d} \delta / \mathrm{dt}=\dot{\delta}_{-}+\dot{\delta}_{+} \cdot
$$

is therefore controlled by the competition between the rates of ion collection and sputtering. 
Detalled Information on the temporal and spatial evolution of the surface and subsurface alloy composition can be obtained by solving eqs. (23) and (27) numerically for a sami-infinite medium, starting from the thermodynamic equilibrium conditions. The moving boundary was accommodated for by the same transformation as that used in section 3.1 . The first two atom layers were tre-ced discretely in order to laclude the effect of GA [71]. Sample calculations were performed for low- and high-energy $\mathrm{SI}^{+}$and $\mathrm{Al}^{+}$implantations into $\mathrm{N1}$ [55]. It has been knjwn from previous studies that in Irradiated $\mathrm{N} 1$, Si atoms segregate in the same direction as the defect fluxes, whereas $\dot{A} l$ solutes migrate in the opposite direction [40]. Thus, the effects of different segregation mechanisms could be examined with the prasent model.

Redistributions of $\mathrm{Al}$ and $\mathrm{Si}$ solutes in $\mathrm{N1}$ during 50-keV implantation at $500^{\circ} \mathrm{C}$ are presented In flgs. 6 and 7 , respectively. The normalized rates of defect production and ion deposition, calculated with the TRIM code [59], are included in the top portfons. The most-probable damage and Ion ranges for $\mathrm{Al}^{+}$and $\mathrm{Si}^{+}$ions are $\mathrm{R}_{\mathrm{d}}=13$ and $12 \mathrm{~nm}$, and $\mathrm{R}_{1} \simeq 27$ and $24 \mathrm{~nm}$, respectively. For the ion flux used, $6.25 \times 10^{13}$ Ions $/ \mathrm{cm}^{2} \mathrm{~s}$ (1.e., $10 \mu \mathrm{A} / \mathrm{cm}^{2}$ ), the calculated peak-damage rates were $\mathrm{K}_{0}^{\max }=7.92 \times 10^{-2}$ and $8.63 \times 10^{-2} \mathrm{dpa}$ is for the respective $\mathrm{Al}^{+}$and $\mathrm{Si}^{+}$bombardments of $\mathrm{N} 1$. The effective defect-production rate $K$ was estimated by multiplying the calculated rate by a defect-production efficiency of $0.3[60]$. The sputtering coefficlents for the host and solute atoms, $S_{B}(B=N i)$ and $S_{A}$, In $\mathrm{Ni}-\mathrm{Al}$ and $\mathrm{NI} \cdot-\mathrm{Si}$ alloys were taken to be 3.5 and 2.0 atoms/1on, and 3.5 and 1.0 atoms/ion, respectively [72]. Here, $S_{A}$ and $S_{B}$ were assumed to be equal to the coefficlents for the pure $A$ and $B$ elements. Since sputtering Is significant at $50 \mathrm{keV}$, the bombarded surface recedes into the sample 
with time. The surface displacements $\delta$ are indicated in the figures. In the Al-1mplantation case ( $f i g, 6), \mathrm{C}_{\mathrm{Al}}^{(1)}$ increases with time to a steadystate value of $\sim 50$ at.\%, which is governed by the partial sputtering coefficient of the implant, $S_{A l}$. This value is substantially larger than that obtalned in very high-energy implantation, where sputtering is negligible and $C_{A l}^{(1)}$ is controlled by RIS. However, the total implant concentration remaining in the sample is significantly smaller because of sputtering. Furthermore, the shape of the eteady-state implant profile is dictated by PS, RED and RIS.

The evolution of the Si profile (fig. 7) is rather different from that of Al, because of the different RIS behaviors. After a short implantation time, Si enrichment occurs at the surface because of RIS, and the Si distribution peak starts noving into the sample interior. With increasing time, $\mathrm{C}_{\mathrm{Si}}^{(1)}$ increases monotonically, attaining a steady-state value of $\sim 100$ at.\% at $\mathrm{t} 22 \times 10^{4} \mathrm{~s}$. This value is predicted because $\mathrm{S}_{\mathrm{S} I}=1$ atow/ion. Unlike the Al case, the SI profile shows a significant shift of the implant distribution into the beyond-range region. At steady state, the peak of the distribution is at $90 \mathrm{~nm}$ from the surface, 1.e., about four times the ion most-probable range. In addition, high-level tails extending deep into the sample can be observed behind the distribution peak for long implantations. The predicted translation of the Si-distribution peak into the sample interior was consistent with recent experimental measurements by Mayer et al. [73] in St-implanted $\mathrm{N} 1$ at elevated temperatures. The propagation of the implant concentration peak into the bulk was also reported by Watkins 174 ; for $60-\mathrm{keV} \mathrm{Cu}^{+}$implantation into $\mathrm{Ti}$. 


\section{Sumary and conclusion}

The complex interplay of vartous processes, including preferential sputtering, displacement mixing, radiation-enhanced diffusion, radiationInduced segregation and Gibbsian adsorption, in altering the subsurface alloy composition during elevated temperature bombardment has been reviewed. In general, considerable progress has been made, both theoretically and experimentally, during the recent years in identifying the relative importance of the Individual processes under varfous irradiation conditions. The phenomenon of bombardment-induced compositional redistribution is simplest at low temperatures where only the athermal processes, i.e. preferential sputtering and displacement mixing, are dominant. The thickness of the resulting compositionally-altered layer is approximately equal to the ion range. As temperature is increased, the radiation-induced point derects become increasingly mobile, and radiationenhanced diffusion, radiation-induced segregation and Gibbsian adsorption affect the extent of, and the composition $1 \mathrm{n}$, the altered layer. The depth of this layer can become orders of masnitude larger than the range of the sputter ions, because polnt defects can migrate deep into the undamaged microstructure well beyond the defect production region. The increased altered-layer thickness causes a corresponding increase in transient time necessary to reach steady state. In the case of inert-gas ion sputtering of alloys, the steady-state composition at the sputtered surface is always determined by preferential sputtering (which 1ncludes the partial sputtering coefficients and the contribution from beneath the first atom layer to the sputtered-atom $f(u x)$ and the bulk composition of the alloy. On the other hand, for the case of Ion Implantation of metals, the steadystate surface composition is predominantly controlled by the partial 
sputtering coefficlent of the implanted solute; the shape of the implant profile is dictated by preferential sputtering, in addition to radiationenhanced diffusion and radlation-induced segregation.

The aultitude of processes that affect surface layer composition during Ion bombardment can provide a good flexibility in modifying alloy surfaces. It is now evident that a wide variety of microstructures, and phase and composition distributions can be produced in near-surface regions of alloys by appropriate choices of energy, type and flux of the bombarding lons, the 1rradiation temperature, and the 1nitial structure and composition of the target. This flexibility is also extremely beneficial for future experimentatin to further our understanding of the complex phenomenon of bombardment-induced compositional segregation and redistribution.

Acknowledgements

The authors would like to acknowledge many stimulating discussions with their colleagues at ANL on the topics covered in this paper. 
References

[1] H. H. Andersen, In: Phystes of Iuntzed Gases (SPIG 1930), Ed. M. Matie (Borls Kidrie Instituce of Nuclear Sclences, Beograd, 1980) p. 421 .

[2] G. Betz, Surface Sc1. 92 (1980) 283.

[3] R. Kel1y, Surface Sc1. 100 (1980) 85.

[4] R. Kelly, In: Symposium on Sputtering, Eds. P. Varga, G. Betz, and F。 P. Vieböck (Institut für Allgemelne Physik, Vienna, 1980) p. 390.

[5] G. Betz and G. K. Wehner, In: Sputtering by Particle Bombardment II, Ed. R. Behrisch (Springer-Verlag, Berlin, 1983) p. 11.

[6] N. Q. Lam, G. K. Leaf and H. Wiedersich, J. Nuc1. Mater. 88 (1980) 289.

[7] L. E. Rehn, S. Danyluk and H. Wiedersich, Phys. Rev. Letters 43 (1979) 1764.

[8] N. Q. Lam and H. Wledersich, J. Nucl. Mater. 103/104 (1981) 433.

[9] N. Q. Lam and H. Wiederslch, Mater. Res. Soc. Symp. Proc. 7 (1982) 35.

[10] H. Wlederstch, H. H. Andersen, N. Q. Lam, L. E. Rehn and H. W. Plckering, 1n: Surface Modification and Alloy1ng, Eds. J. M. Poate, G. Foti and D. C. Jacobson, NATO Series on Materials Science (Plenum, New York, 1983) p. 261。

[11] N. Q. Lam, H. A. Hoff, H. Whedersich and L. E. Rehn, Surface Sci. 149 (1985) 517.

[12] N. Q. Lam, H. A. Hoff and P. G. Régnier, J. Vac. Sci. Technol. A 3 (1985) 2152. 
[13] L. E. Rehn and N. Q. Lam, 1n: Proc. Symp. on Surface Segregation and SeIf-Renewing Coatings (American Society for Metals, Metals Park, OH, 1986) in press.

[14] P. Sigmund, Phys. Rev. 184 (1969) 383.

[15] N. Andersen and P. S1gmund, Mat. Fys. Medd. Dan. V1d. Se1sk. 39 (1974).

[16] G. Falcone and P. Siguund, App1. Phys. 25 (1981) 307.

[17] H. H. Andersen, App1. Phys. 18 (1979) 131.

[18] U. Luttmark and H. O. Hofer, Nucl. Instr. Meth. 168 (1980) 329.

[19] P. Sigmund and A. Gras-Mart1, Nuc1. Instr. Meth. 182/183 (1981) 25.

[20] S. Matteson, B. M. Paine and M. A. Nicolet, Nucl. Instr. Meth. $182 / 183(1981) 53$.

[21] P. Sigmund, App1. Phys. A30 (1983) 43.

[22] B. M. Paine and R. S. Averback, Nucl. Inst. Meth. B7/8 (1985) 666 .

[23] R. S. Averback, Nucl. Instr. Meth. B15 (1986) 675.

[24] H. Wiedersich, Nucl. Instr. Meth. B 7/8 (1985) 1.

[25] W. E. King and R. Benedek, J. Nucl. Mater. 117 (1983) 26.

[26] M. A. Kirk and T. H. Blewitt, Met. Trans.A9 (1578) 1729; J. Nuc1. Mater. 108/109 (1982) 124.

[27] R. H. Zee, M. W. Guinan and G. L. Kulcinski, J. Nucl. Mater. 114 (1983) 190.

[28] Y. T. Cheng, M. Van Rossum, M. A. Nicolet and W. L. Johnson, Appl. Phys. Letters 45 (1984) 185.

[25] F. d'Heurle, J. E. E. Baglin and G. J. Clark, J. App1. Phys. 57 (1985) 1426.

[30] S. J。 Kin, M. A. Nicolet, R. S. Ayerback and P. Baldo, App1. Phys. Letters $46(1985) 154$. 
[31] R. S. Averback, D. Peak and L. J. Thompson, App1. Phys. A 39 (1986) 59.

[32] H. Wiedersich, P. R. Okamoto and N. Q. Lam, J. Nucl. Mater. 83 (1979) 98.

[33] H. Wiedersich and N. Q. Lam, in: Phase Transformations during Irradiation, Ed. F. V. Nolfi, Jr. (Applied Science Publishers, London, 1983) P. 1 .

[34] Y. Adda, M. Beyeler and G. Brebec, Thin Solld Films 25 (1975) 107.

[35] N. Q. Lam and S. J. Rothman, in: Radiation Damage in Metals, Eds. N. L. Peterson and S. D. Harkness (American Society for Metals, Metals Park, Oh1o, 1976) p. 125.

[36] R. Sizmann, J. Nucl. Mater. 69/70 (1978) 386.

[37] S. J. Rothman, 1n: Phase Transformations during Irradiation, Ed. F. V. Nolf1, Jr. (Applied Sclence Publishers, London, 1983) p. 189.

[38] R. A. Johnson and N. Q. Lam, Phys. Rev. B13 (1976) 4364; J. Nucl. Mater. 69/70 (1978) 424.

[39] N. Q. Lam, A. Kumar and H. Wledersici, in: Effects of Radiation on Materials - Eleventh Conference, ASTM STP782, Eds. H. R. Brager and J. S. Perrin (American Society for Testing and Materials, Ph1ladelphia, PA, 1982) p. 985.

[40] L. E. Rehn and P. R. Okamoto, 1n: Phase Transformations during Irradiation, Ed. F. V. Nolf1, Jr. (Applled Sctence Publishers, London, 1983) p. 247.

[41] H. Wiedersich, In: Physics of Radiation Effects in Crystals, Eds. R. A. Johnson and A. N. Orlov (Elsevier Sclence Publisher, London, 1985) p. 225 . 
[42] P. Wynblatt and $R_{0}$ C. Ku, In: Interfacial Segregation, Eds. W. C. Johnson and J. M. Blakely (American Society for Metals, Metals Park, Ohio, 1979) p. 115.

[43] M. J. Kelley, P. W. Gilmour, and D. G. Swartzfager, J. Vac. Sc1. Technol. 17 (1980) 634.

[44] N. Q. Iam and H. A. Hoff, to be published.

[45] H. H. Brongersma and T. M. Buck, Surface Sc1. 53 (1975) 649.

[46] H. H. Brongersma, M. J. Sparnaay and T. M. Buck, Surface Scl. 71 (1978) 657 .

[47] C. R. Helms, J. Catalysis 36 (1975) 114.

[48] C. R. Helms and K. Y. Yu, J. Vac. Sc1. Technol. 12 (1975) 276.

[49] K. Watanabe, M. Hashiba and T. Yamash1na, Surface Sci. 61 (1976) 483.

[50] J. J. Burton, C. R. Helms, and R. S. Polizzotti, J. Vac. Sci. Technol. $13(1976) 204$.

[51] Y. S. Ng, T. T. Tsong and S. B. McLane, Jr., Phys. Rev. Letters 42 (1979) 588.

[52] Y. S. Ng, S. B. McLane and T. T. Tsong, J. Vac. Sci. Technol. 17 (1980) 154.

[53] T. Sakurai, T. Hashizume, A. Jimbo and A. Sakal, Phys. Rev. Letters $55(1985) 514$

[54] L. E. Rehn, H. A. Hoff and N. Q. Lam, Phys. Rev. Letters (1986) to be published.

[55] N. Q. Lam and G. K. Leaf, J. Mater. Res. 1 (1986) in press。

[56] N. Q. Lam and H. Wledersich, Rad. Eff. Letters 67 (1982) 107.

[57] L. E. Rehn, N. Q. Lam and H. Wedersich, Mat. Res. Soc. Symp. Proc. 27 (1984) 37; Nucl. Instr. Meth. B7/8 (1985) 764. 
[58] A. R. Krauss, A. B. DeWald, D. M. Gruen and N. Q. Lam, Rad. Eff. 89 (1985) 129.

[59] J. P. Biersack and I. G. Haggmark, Nucl. Instr. Meth. 174 (1980) 257.

[60] P. R. Okanoto, L. E. Rehn and R. S. Averback, J. Nucl. Mater. 133/134 (1985) 373.

[61] H. Shimizu, M. Ono and K. Makayama, J. Appl. Phys. 46 (1975) 460.

[62] L. E. Rehn and H. Wiedersich, Thin Solid Films 73 (1980) 139.

[63] D. G. Swartzfager, S. B. Zlemecki and M. J. Kelley, J. Vac. ScI. Technol. 19 (1981) 185.

[64] P. S. Ho, Surface Sc1. 72 (1978) 253.

[65] R. S. Nelson, Phil. Mag. 11 (1965) 291.

[66] P. S. Ho, J. E. Lewis, H. S. Wildman and J。 K. Howard, Surface ScI. $57(1976) 393$.

[67] R. Kelly and A. Oliva, Nucl. Instr. Meth. 313 (1986) 283.

[68] H. H. Andersen, B. Stenum, T. S $\phi r e n s e n$ and H. J. Whitlow, Nucl. Instr。 Meth. B2 (1984) 623.

[69] H. Shtmizu, M. Ono, N. Koyama and Y. Ishida, J. App1. Phys. 53 (1982) 3044.

[70] A. Barbu, Acta Metall. 28 (1980) 499.

[71] N. Q. Lam and G. K. Leaf, to be published.

[72] H. H. Andersen and H. L. Bay, in: Sputtering by Particle Bombardment, Ed. R. Behrisch (Springer, Heidelberg, 1981) p. 145.

[73] S. G. B. Mayer, F. F. M111110 and D. I. Potter, Mat. Res. Soc. Symp. Proc. 39 (1985) 521.

[74] R. E. J. Watkins, Rad. Effects 84 (1985) 27. 
Table l: ISS measurements of $\Delta \mathrm{S}_{\mathrm{a}}$ and $\Delta \mathrm{H}_{\mathrm{a}}$ for $\mathrm{Ni}-\mathrm{Au}$ [12], $\mathrm{Ni}-\mathrm{Cu}$ [11] and N1-S1 [44] alloys.

N1-6 at.\% Au

$-1.09$

$-0.45$
$\mathrm{Ni}-40$ at. $\% \mathrm{Cu}$

$\mathrm{Ni}-9.5$ at.\% S1

$-2.60$

0.26

$\Delta \mathrm{H}_{\mathrm{a}}(\mathrm{eV})$

$-0.42$

$-0.054$ 


\section{FIGURE CAPTIONS}

Fig. 1. Temperature dependence of the ISS intensity ratio measured on Ni40 at.\% $\mathrm{Cu}$ and $\mathrm{iNI}-6$ at.\% Au alloys maintalned at thermal. equilibrium.

Fig. 2. Calculated rime evolution of $\mathrm{Cu}$ concentration profiles in a Ni-40 at.\% $\mathrm{Cu}$ alloy sputtered with $3-\mathrm{keV} \mathrm{Ne}^{+}$ions at $500^{\circ} \mathrm{C}$. The profile of the damage rate $\mathrm{K}$ is shown by the dashed curve in the top portion, and the thickness of the surface layer removed by sputtering is indicated. The energies for vacancy migration via $\mathrm{Cu}$ and $\mathrm{N} 1$ atoms were taken to be 0.95 and $0.97 \mathrm{eV}$, respectively.

Fig. 3. (A) Calculated time evolution of the composition in the outermost trom layer of a $\mathrm{Ni}-40$ at.\% Cu alloy during $3-\mathrm{keV} \mathrm{Ne}^{+}$sputtering at various temperatures. Two sets of initial conditions were used: the thermodynamic equilibrium state of the alloy (solid curves), and the nonequilibrium uniform alloy composition (dotted curves). (B) The corresponding compositional profiles at steady state. The vertical line indicates the boundary between the first and second atomic layers. The migration energles of vacarcies and interstitial via $\mathrm{Cu}$ and $\mathrm{Ni}$ atoms are tabulated. The symbois are used simply to label the curves for different temperatures.

Fig。 4. Time evolution of the $\mathrm{Cu} / \mathrm{Ni}$ ISS intensity ratio measured during $3-\mathrm{keV} \mathrm{Ne}{ }^{+}$sputtering of a $\mathrm{Ni}-40$ at.\% $\mathrm{Cu}$ alloy at various temperatures $[11]$.

F1g. 5. Steady-state concentration profiles of the altered layers in a $\mathrm{NI}-$ 40 at.\% $\mathrm{Cu}$ alloy after sputtering with $3-\mathrm{keV} \mathrm{Ne}^{+}$tons at varfous temperatures. The dashed vertical line indicates the boundary between the first and second atom layers [11]. 
Fig. 6. Develoment of the Al profiles during 50-keV 1mplantation at $500^{\circ} \mathrm{C}$. The normalized damage $\left(\mathrm{K}_{\mathrm{o}}\right)$ and ion-deposition $\left(\mathrm{P}_{\Delta \mathrm{x}}\right)$ rates are shown in the top portion, and the surface displacements $\delta$ resulting from sputtering are indicated. Note that the concentration scales are multiplied by factors shown in each plot $[55]$.

Fig. 7. Time evolution of the Si profiles during 50-keV implantation at $500^{\circ} \mathrm{C}$. The normalized damage and ion-deposition rates are shown In the top portion. Surface displacements $\delta$ resulting from sputtering are indfcated. Note that the depth scales in plots for $t=0.1 \mathrm{~s}$ and $t>10 \mathrm{~s}$ differ by a factor of 5 and the concentration scales are multiplied by factors shown near the curves [55]. 


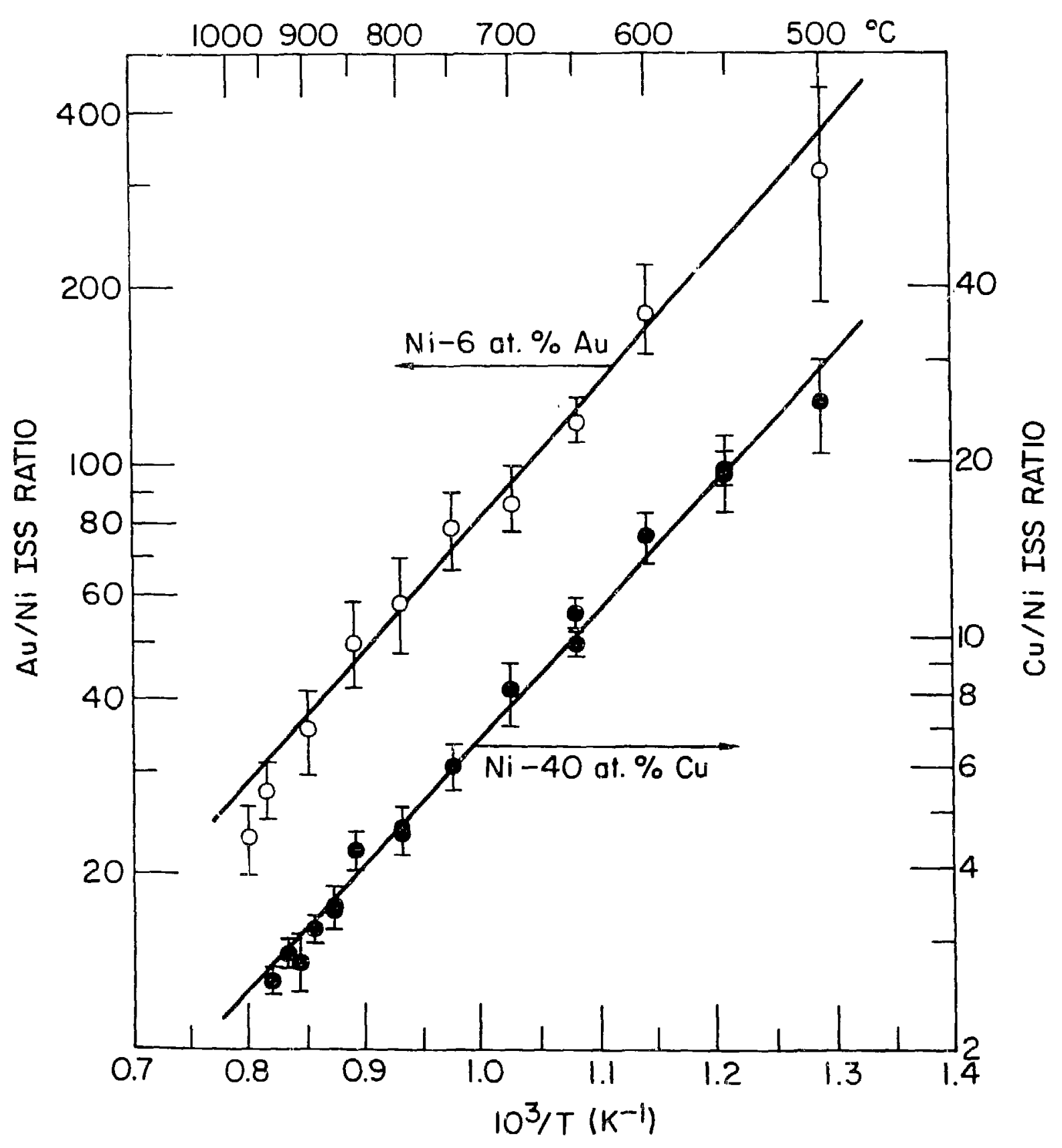

FIGURE 1 


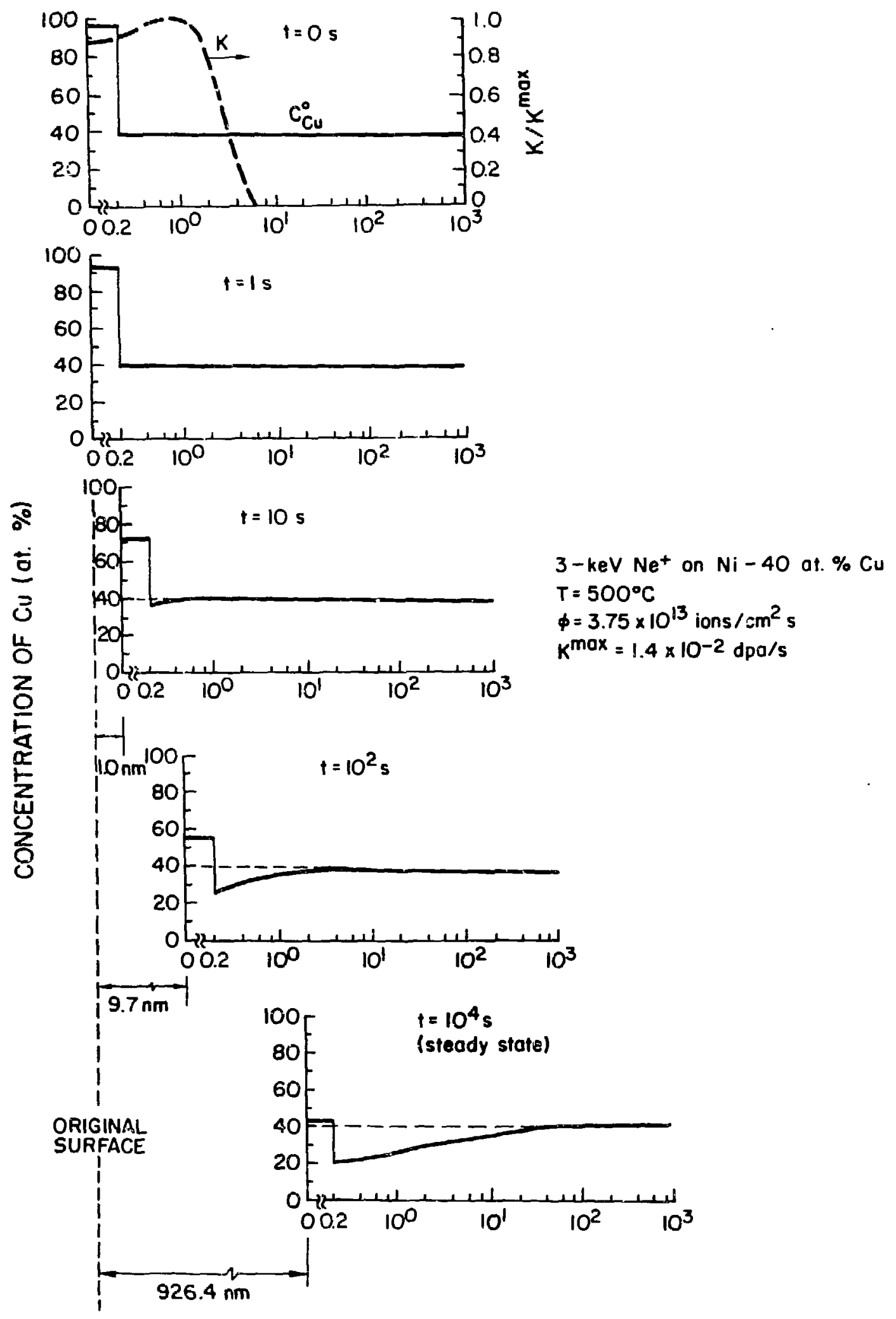

DISTANCE FROM SURFACE $(\mathrm{nm})$ 

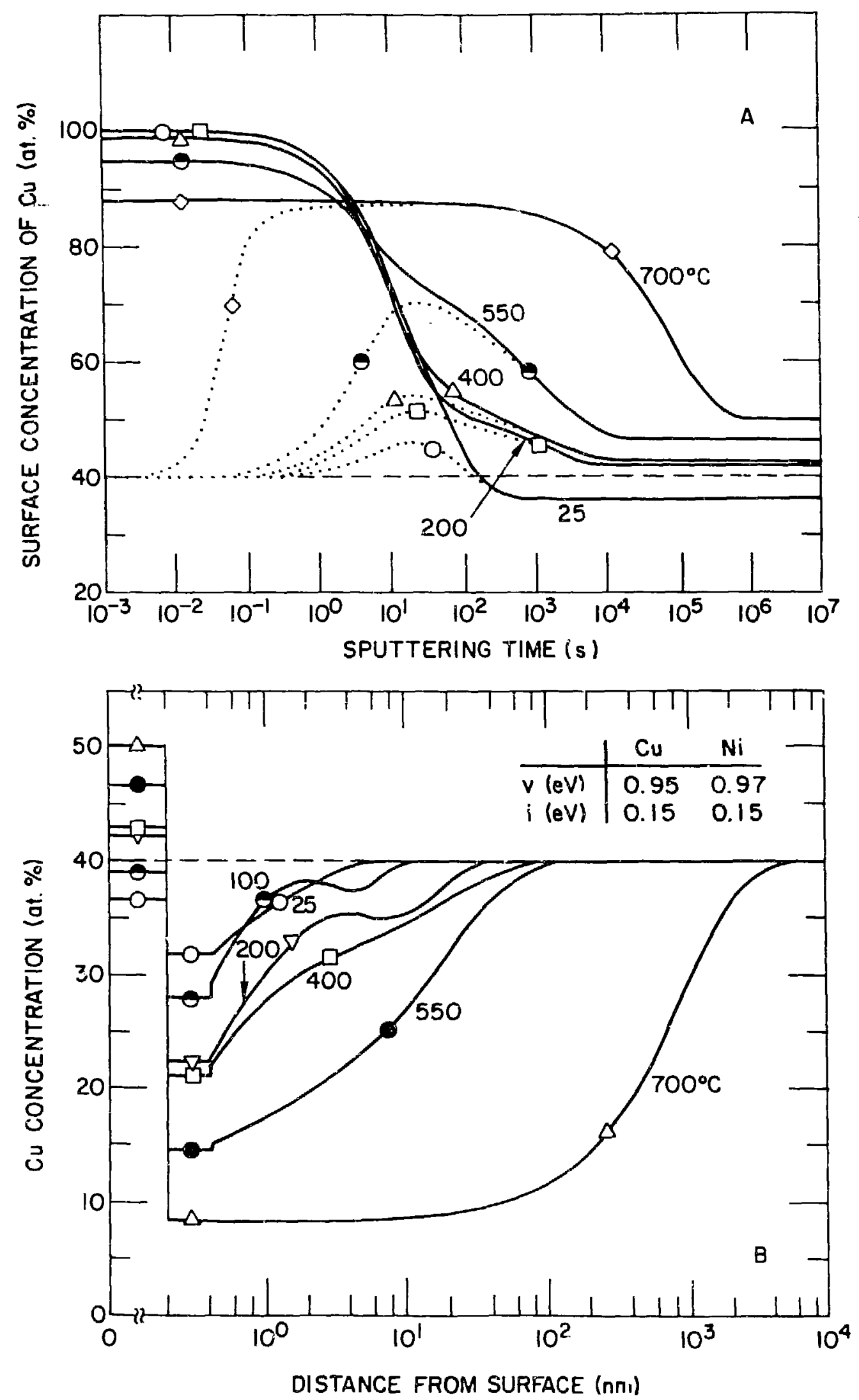

FIGURE 3 


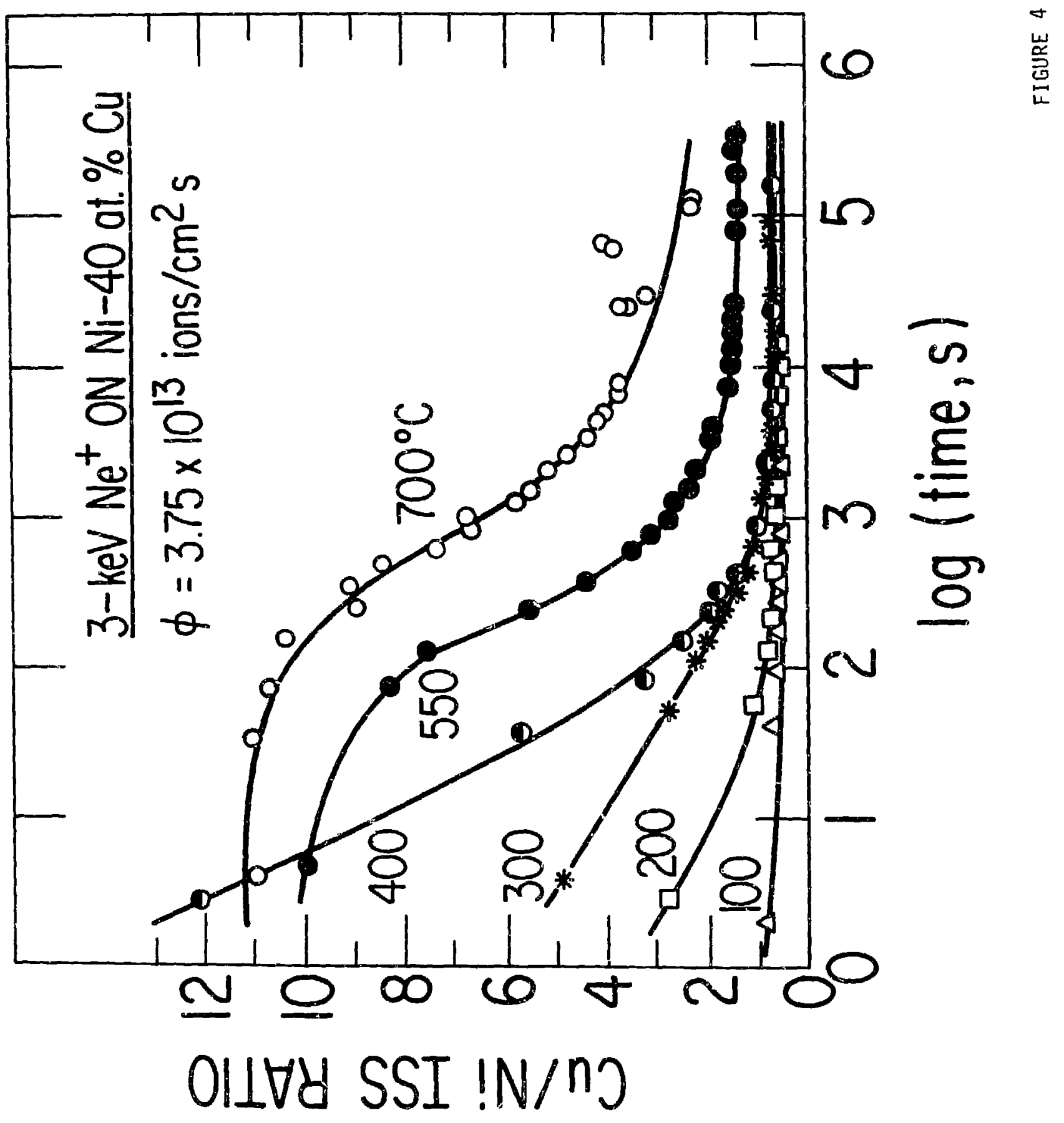




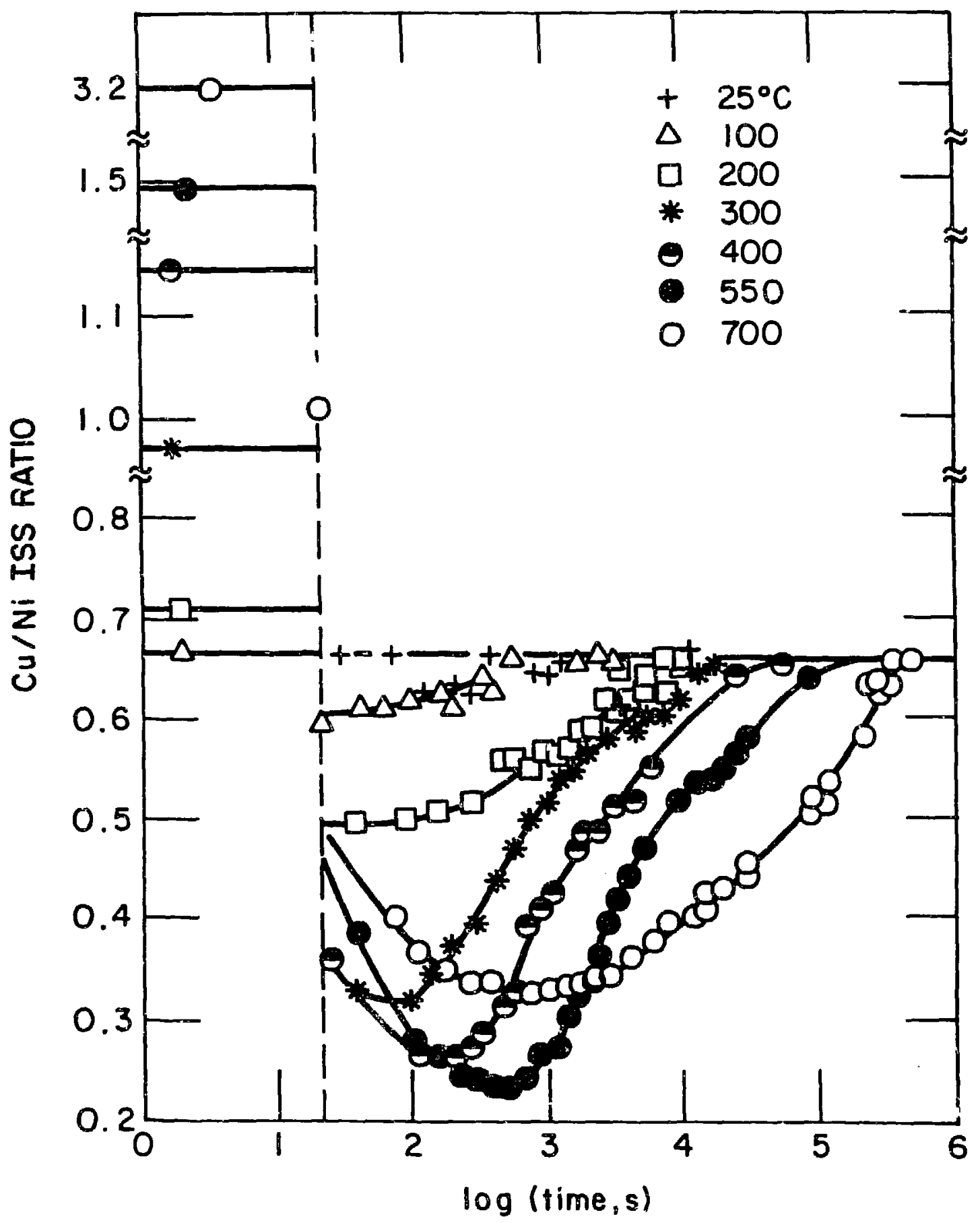

FIGURE 5 


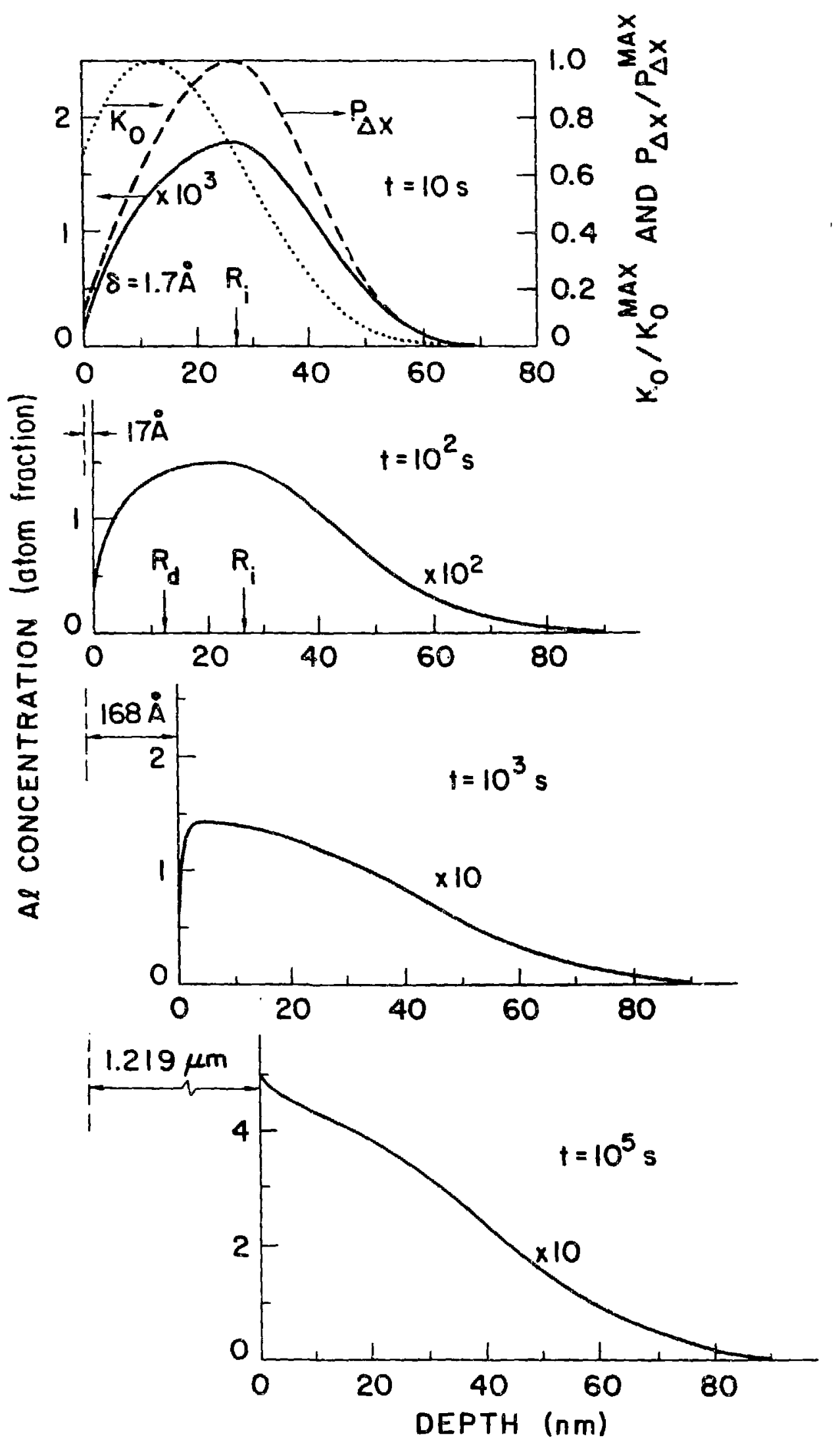



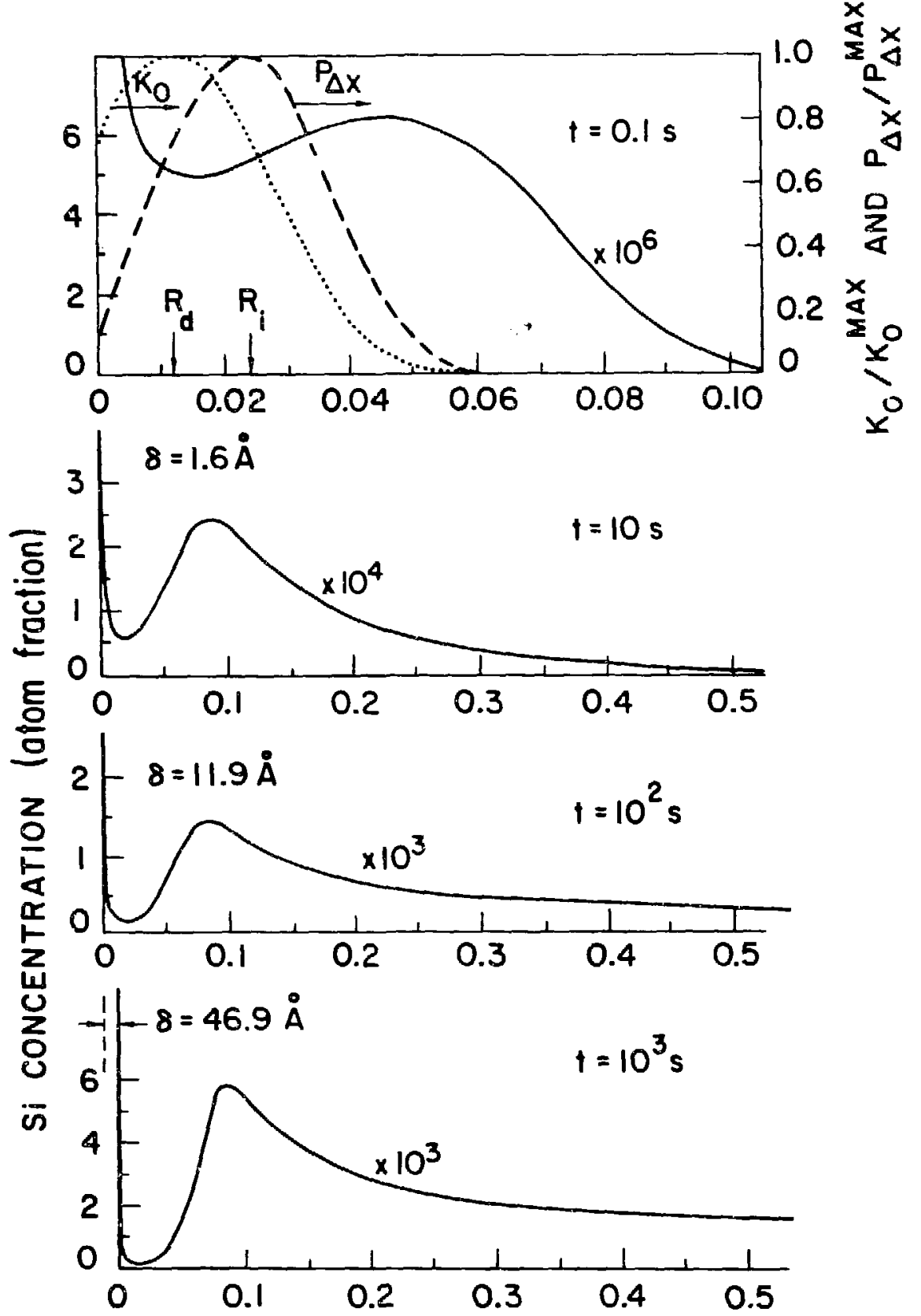

\section{$8=183.8 \AA$}

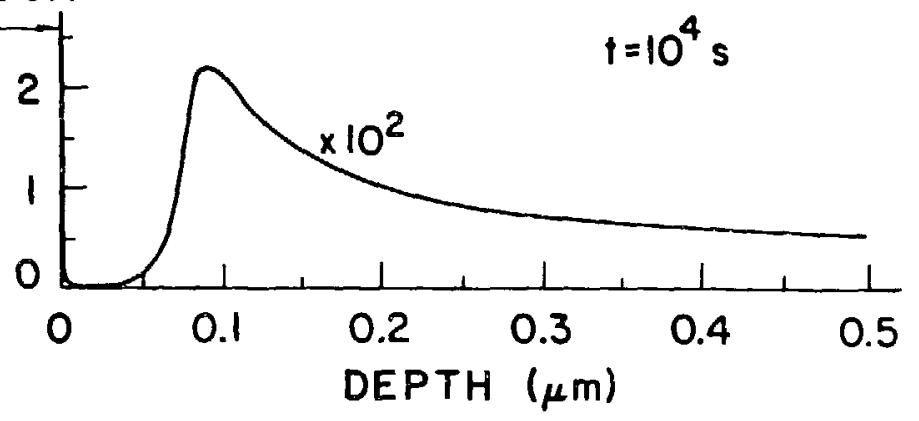

